\title{
La noción de criatura viva en el naturalismo cultural de John Dewey*
}

\author{
The notion of living creature \\ in John Dewey's cultural naturalism
}

\author{
Por: Gloria Luque Moya \\ Universidad Nacional de Educación a Distancia \\ Málaga, España \\ E-mail: gloluque@malaga.uned.es \\ ORCID: 0000-0002-7626-3961
}

Fecha de recepción: 30 de abril de 2018 Fecha de aprobación: 10 de junio de 2018

Doi: 10.17533/udea.ef.n59a06

Resumen. El término naturalismo se presenta problemático en el contexto actual ya que agrupa corrientes filosóficas y pensadores muy dispares. Algunos autores contemporáneos, como David Papineau, han propuesto ordenarlos en torno a dos vertientes diferenciadas: la ontológica, que se ocupa de los contenidos de la realidad; y la metodológica, que atiende a los modos de investigar esa realidad. En términos generales, el naturalismo de John Dewey, al igual que el de James y Rorty, se ha definido como metodológico. Sin embargo, a través del análisis de la noción de criatura viva, este artículo intenta evidenciar cómo el naturalismo deweyano también ha de ser estudiado desde la dimensión ontológica. Para ello, en primer lugar, atenderá a las diferentes corrientes y autores que contribuyen a la evolución desde el término deweyano de organismo hasta el de criatura viva. Después subrayará la continuidad entre criatura y medio que mantiene la ontología emergentista de Dewey y el potencial de dicha interacción.

Palabras claves: organismo, experiencia, naturaleza, Alexander, continuidad

* El presente artículo es una reflexión original con base en la investigación doctoral previa en la Universidad de Granada y ha sido posible gracias a la financiación recibida por la Beca Nacional del programa de Formación del Profesorado Universitario concedida por el Ministerio de Educación del Gobierno de España.

Cómo citar este artículo:

MLA: Luque Moya, Gloria. "La noción de criatura viva en el naturalismo cultural de John Dewey". Estudios de Filosofía, 59 (2019): 121-138.

APA: Luque Moya, G. (2019). La noción de criatura viva en el naturalismo cultural de John Dewey. Estudios de Filosofia, $59,121-138$.

Chicago: Gloria Luque Moya. "La noción de criatura viva en el naturalismo cultural de John Dewey". Estudios de Filosofia n. ${ }^{\circ} 59$ (2019): 121-138. 
Abstract. The term 'naturalism' is problematic in the current context since it comprises a set of very different philosophical traditions and thinkers. Some contemporary authors, such as David Papineau, have proposed grouping them according to two different components: the ontological component, which is concerned with the contents of reality; and the methodological one, which is concerned with the way of investigating reality. In general terms, John Dewey's naturalism, the same as Perice's and Rorty's ones, has been defined as methodological. However, through the analysis of the notion of living creature, this article attempts to show how Deweyan naturalism also needs to be understood from its ontological dimension. First, it deals with the different philosophical currents and authors which contribute to the evolution from the Deweyan term of organism to the living creature. Then, it outlines the continuity between the creature and its surroundings that affirms Dewey's emergent ontology and the potential of this interaction.

Keywords: organism, experience, nature, Alexander, continuity

\section{Introducción: Contextualización del naturalismo de John Dewey}

El naturalismo es una aproximación filosófica compleja que ha generado un debate controvertido sobre la interpretación y plausibilidad de esta propuesta. En la actualidad se pueden distinguir enfoques del naturalismo muy dispares y alejados. Susan Haack (1993) ha recogido un total de nueve enfoques en su obra Evidencia e investigación: hacía la reconstrucción en epistemología (pp. 118-119). David Papineau (2015), por su parte, ha distinguido dos dimensiones básicas en las que se desarrolla esta disputa: una de ellas se ocupa de lo que existe, lo real; la otra del método para adquirir conocimiento. Es decir, se diferencian dos corrientes: una ontológica que examina los contenidos de la realidad sin acudir a ningún tipo de elemento que se encuentre fuera de la naturaleza; y otra metodológica que considera los modos de investigar la realidad, otorgándole cierta primacía al método científico.

Estas dos vías han sido exploradas a lo largo del tiempo por diferentes filósofos y tradiciones, atribuyéndole una caracterización propia. En este contexto resalta el papel que juega la tradición pragmatista con filósofos como Charles Sanders Peirce, William James, John Dewey o Richard Rorty. Estos autores consideran el problema de la epistemología desde un enfoque antifundacionalista y falibilista que une el significado y las consecuencias experimentales.

Sin embargo, el naturalismo que Dewey desarrolla en la etapa final de su pensamiento no puede ser reducido exclusivamente a este enfoque metodológico. Desde su propuesta naturalista, el filósofo norteamericano desarrolló un enfoque doble: por un lado, realizó un estudio sobre las características genéricas de la 
realidad, que excluía toda instancia ajena a lo natural; por otro lado, propuso un análisis sobre los modos de investigar la realidad. A diferencia de la corriente pragmatista, Dewey propone un naturalismo que pone el énfasis en la capacidad creativa del hombre para construir la realidad y advierte que éste no es propio ni exclusivo de la ciencia, sino de la indagación inteligente en cualquier ámbito de la vida. Así leemos en Experiencia y naturaleza (1925 [1989a]):

Todas las actividades inteligentes de los hombres, no importa si se expresan en la ciencia,
en bellas artes o en las relaciones sociales, tienen por tarea el convertir los lazos causales,
las relaciones de sucesión, en una conexión de medios-consecuencia, en significados
(EN, LW 1, p. 277). ${ }^{1}$

Una de las nociones claves de su propuesta naturalista será la reinterpretación del ser humano como criatura viva que realiza en su periodo final. Este término es sumamente relevante en la construcción del naturalismo cultural que Dewey desarrolla; no obstante, no se ha atendido a él con suficiente atención por la visión sesgada que llega del naturalismo deweyano a través de la interpretación de Richard Rorty. Siguiendo a Quine, Rorty desarrolla un naturalismo que sólo atiende al enfoque epistemológico y reduce la aproximación ontológica de la propuesta deweyana a un mero desvarío metafísico. Rorty ataca duramente a la noción de "existencia metafísica" y la sitúa en lo que se podría denominar "la parte oscura de Dewey", "el mal Dewey", cuya reflexión se centra en cuestiones metafísicas (Rorty, 1982, pp. 73-74).

Esta aproximación ha propiciado, como ha destacado Thomas Alexander, que nos llegue un retrato realizado desde los intereses del artista, en este caso Rorty, en lugar de ser fiel a la obra (Alexander, 2013, p. 3). La interpretación de Rorty, por tanto, hace que la filosofía deweyana pierda sentido, y divida la figura de Dewey en "el bueno" y "el malo". "El bueno" será aquel que postula la crítica de la cultura en obras como La reconstrucción de la filosofía (1920) y La búsqueda de la certeza (1929); "el malo", aquel que sucumbe a la metafísica presentada en Experiencia y naturaleza. Para bien o para mal, dirá Rorty, Dewey quiso desarrollar un sistema metafísico, para resolver los problemas epistemológicos (Rorty, 1982, p. 73).

1 Las referencias a los escritos de John Dewey se basarán en la edición crítica de las obras completas publicada por Southern Illinois University: EW (The Early Works), MW (The Middle Works) y LW (The Later Works). Las citas seguirán el modelo normalizado entre los estudiosos de la obra de Dewey: la abreviación de la obra, la inicial de las series, seguida por el volumen y el número de la página. Además se incluirá la referencia a la traducción, si la hubiese, y el número de página. 
Sin embargo, el naturalismo deweyano no puede ser comprendido exclusivamente desde su dimensión metodológica. Siguiendo las aproximaciones realizadas por diversos especialistas de la filosofía deweyana, este artículo reivindica la dimensión ontológica del naturalismo deweyano a partir de un análisis de la noción de criatura viva. En primer lugar, analiza los principales influjos que conforman este concepto. En segundo lugar, considera el concepto de criatura viva, expuesto en Experiencia y naturaleza (1925 [1989a]) y El arte como experiencia (1934 [1989c]), destacando la importancia e influencia de Frederick Matthias Alexander. En tercer lugar, expone cómo la noción de criatura viva no puede ser entendida sin el entorno en el que se desarrolla. De este modo, se trata de evidenciar cómo, pese a las variaciones a lo largo de su proyecto filosófico, este término se muestra como elemento clave para entender esa relación hombre-naturaleza, caracterizada por su continuidad, por su continuo devenir en el acontecer de las situaciones.

\section{Principales influencias en la noción de "organismo"}

El concepto de criatura viva lo encontramos desde los inicios del pensamiento de John Dewey y, pese a los matices que van introduciéndose a lo largo de su desarrollo, se mantendrá como elemento clave para entender su proyecto filosófico. Esta primera sección realiza una síntesis de las principales influencias y características que constituyen este término. Hay que tener presente que el filósofo estadounidense introduce la noción de criatura viva en su obra El arte como experiencia (1934 [1989c]), como punto de partida para restaurar la continuidad entre las Bellas Artes y el devenir cotidiano (AE, LW 10, p. 9; Ae, p. 4); hasta entonces rastrearemos los orígenes de esta noción en el término de "organismo".

En otras palabras, la noción de criatura viva será una nueva denominación de su concepto inicial de organismo, en el que confluyen la fisiología de Wundt y Huxley, el idealismo alemán y Hegel, el propio Darwin y el pragmatismo. Estas corrientes y disciplinas tan diferentes en su modalidad tenían como elemento común la noción de organismo, que Dewey toma y hace propia. Es decir, como el propio autor explica en su artículo "La nueva psicología" (1884), el concepto funcional de organismo, común a la biología y al idealismo, le ofrecía el vínculo conector entre estas corrientes (EW 1, pp. 55-56).

Dewey emplea el término "organismo" desde sus inicios, tras la lectura de las lecciones de Thomas Henry Huxley Psicología elemental (1866), las cuales le 
dejaron una profunda huella. El filósofo estadounidense tuvo acceso a la obra a través de un curso de fisiología que recibió cuando era estudiante en la universidad de Vermont. El propio autor le atribuye una gran importancia porque le condujo a desear un mundo y una vida que tuvieran las mismas propiedades de interrelación e interdependencia que tiene el organismo humano. Así lo pone de manifiesto en su ensayo "Desde el absolutismo al experimentalismo" (1930), dónde explica cómo este curso breve sobre la obra de Huxley le aportó esa idea de unidad interdependiente e interrelacionada que no sólo atribuirá a su propia noción de "organismo", sino que la aplicará al resto de su filosofía (LW 5, pp. 147-8).

Huxley introduce el término "unidad" en la primera sección de sus lecciones, donde explica que el hombre siempre está en movimiento, incluso cuando duerme (Huxley 1915, pp. 3-29). Es decir, todo hombre está compuesto por un conjunto de partes, inmerso en un proceso de continuo cambio. El biólogo analiza las diferentes partes de ese proceso: como el incesante intercambio, consumo y abastecimiento de alimentos y oxígeno, por el cual el cuerpo se autorregula para mantener un equilibrio; la regulación de nuestra temperatura en relación con el ambiente, en constante cambio; o la distribución de la sangre por nuestro cuerpo, incluyendo la ganancia y pérdida de componentes.

Así, Huxley sugirió a Dewey esa idea de interrelación de las partes, de continuo cambio y reestablecimiento de equilibrio, que el filósofo norteamericano aplica a su noción de "organismo", pero también a la propia noción de "vida". Este influjo fisiológico de su primera etapa de pensamiento se ve completado por la psicología wundtiana. Dewey accede a la psicología fisiológica de Wilhelm Wundt a través de su profesor G. Stanley Hall en la John Hopkins University. Hall, inspirado por la obra Principios de la psicología fisiológica de Wundt, se doctoró en 1878 bajo la supervisión de William James, y realizó una estancia breve en los laboratorios de Wundt en Leipzig. De hecho, se llega a autodenominar el primer alumno norteamericano del fisiólogo alemán. Así dice Hall: "Pienso que soy el primer alumno americano de Wundt" (Hall, 1924, p. v).

En relación a la noción de organismo de la que se ocupan estas páginas, hay dos aspectos relevantes que la obra Wilhelm Wundt proporciona a Dewey. La primera de ellas es la noción cuerpo-mente que presenta en su obra Principios de psicología fisiológica (1874). Según éste, la conciencia, cualidad clave en el primer Dewey, es aquella que posee todo ser vivo y que proporciona unidad a los estados internos (Hall, 1924, p. 29). En otras palabras, la unidad cuerpo-mente 
viene dada por la conciencia. Por ello, si queremos establecer un criterio objetivo para su estudio deberemos basarnos en ciertos movimientos corporales que nos indican su origen en los procesos físicos (Wundt, 1910, p. 27).

En segundo lugar, Wundt le proporciona la idea de que las funciones mentales no se infieren por meros movimientos orgánicos, sino por ciertas condiciones que se dan en el medio (Wundt, 1910, p. 31). Esto es, el organismo está en continuo cambio y actúa en relación con su medio. De este modo, no sólo "las funciones mentales son fenómenos de la vida" (Wundt, 1910, p. 27), sino que se originan desde y por la misma. Esto es sumamente relevante, porque dicho enfoque supera, desde la psicología, los dualismos metafísicos heredados a partir de Descartes que oponían lo físico y lo psíquico como ámbitos separados y opuestos. En palabras de Wundt:

\begin{abstract}
La alternativa (física o psíquica) es a menudo presentada como si un concepto necesariamente excluyera al otro, - como, ciertamente, se hizo en el dualismo metafísico de Descartes. Pero esto es confuso. La íntima interconexión de los fenómenos de la vida física y los procesos de la conciencia hace la relación física y psíquica, a primera vista, mucho más probable ${ }^{2}$ (Wundt, 1910, p. 32).
\end{abstract}

La consideración de las influencias que conforman la noción deweyana de organismo se ve completada por la huella del romanticismo alemán y de la filosofía hegeliana. Hegel introdujo el término "vivo" (lebendig) para reconciliar las cualidades materiales y espirituales de la naturaleza. Para Hegel, todo organismo no podía ser explicado desde una perspectiva meramente exterior, sino que había que tener en cuenta la interioridad del ser vivo, su alma (Seele). Así la unidad del organismo vivo es la unidad de lo interior y de lo exterior. Esta alma, este interior, es para Hegel un concepto (Begriff) que mediante su actividad propia se realiza en y con lo corporal. Por eso la contextura orgánica del viviente se corresponde con las diferencias intrínsecas a su concepto (Hegel, 1997, §216).

Como ha señalado Songuk Susan Hahn, los conceptos en Hegel no son abstractos o estáticos, sino vivos, pulsionales, en continuo movimiento (Hahn, 2007 , p. 10). En este sentido, el filósofo alemán propone un concepto de organismo caracterizado por un principio interno que determinara su desarrollo. Según Hegel, el desarrollo del organismo ha de ser controlado o regulado unitariamente, pues la actividad de cada órgano está integrada en la unidad del viviente. La importancia

2 A excepción de las obras que han sido traducidas al español (indicado en las referencias bibliográficas) las citas han sido traducidas por la autora de este artículo. 
de la unidad en el pensamiento hegeliano es tal que la debilidad o ausencia de ésta marca la finitud del viviente; la separación constituye la muerte (Hegel, 1997, §216). Para ilustrarlo recurre al modelo de la planta que había sido reiteradamente usado por los románticos y por el propio Hegel.

El filósofo alemán utiliza esta metáfora en momentos claves de su biografía, como en las introducciones a sus obras mayores: la Fenomenología del espíritu, la Filosofía del derecho o las Lecciones sobre filosofía de la historia universal. En ellas explica cómo la planta primero es semilla, y a partir de ésta, comienza a crecer, convirtiéndose en un árbol, produciendo flores; manifestándose como diferentes momentos interdependientes. De este modo, una planta posee una organización esencial y una conexión entre sus partes agregadas que dan lugar a una totalidad orgánica, revelando aspectos esenciales del proceso dialéctico en sí mismo. En palabras del propio Hegel:

El capullo desaparece al abrirse la flor, y podría decirse que aquél es refutado por ésta; del mismo modo que el fruto hace aparecer la flor como un falso ser allí de la planta, mostrándose como la verdad de ésta en vez de aquélla. Estas formas no sólo se distinguen entre sí, sino que se eliminan las unas a las otras como incompatibles. Pero, en su fluir, constituyen al mismo tiempo otros tantos momentos de una unidad orgánica, en la que, lejos de contradecirse, son todos igualmente necesarios, y esta igual necesidad es cabalmente la que constituye la vida del todo (Hegel, 1966, p. 8).

De esta manera, en un primer periodo, Dewey vislumbra la forma de conciliar esos dos órdenes a través del influjo fisiológico y la noción hegeliana de "organismo". Sin embargo, al igual que ocurrirá con su noción de "naturaleza", la biología darwiniana le proporcionó un nuevo vocabulario y una nueva fórmula que explicará el modo en que surgían nuevas formas, sin recurrir a connotaciones o principios de teleología inmutable o trascendentes. Como el propio Dewey señala en su ensayo La influencia de Darwin en la filosofía (1910 [1983a]), a través de la noción de "especie", Darwin instaura una nueva mirada lógica que supera el problema del diseño versus el azar, o la mente frente a la materia (IDF, MW 4, p.8, IDf, p. 54).

La influencia de Darwin será, pues, crucial porque induce a la investigación filosófica a explorar valores y condiciones específicas, en lugar de perderse en términos de orígenes y finalidades absolutas. Este influjo se puede rastrear en el ensayo inicial "Alma y cuerpo" (1972a), publicado en 1886, donde Dewey expone ya una primera conexión entre el alma y el cuerpo, pero también entre la fisiología, el idealismo y el darwinismo. Para el filósofo estadounidense, el organismo se 
compone de ambos elementos (alma y cuerpo), los cuales funcionan de manera diferente. Por ello, para describirlo usará palabras como "sistema", "tejido nervioso" o "cerebro", así como "alma" o "cuerpo espiritual".

En este ensayo, Dewey establece conexiones entre el alma y los tejidos nerviosos, subrayando cómo la actividad de ambos se inicia por procesos de ajustes ante estímulos o fuerzas, las cuales conllevan un movimiento adaptado a la impresión externa (EW 1, p. 99). Sin embargo, advierte que el carácter teleológico de la acción no hay que atribuirlo a una estructura de la naturaleza en sí misma, sino que Darwin permite desechar esta tendencia al haber establecido una ley general del universo y de las estructuras de las cosas. Por ello, si se considera al organismo como un conjunto en constante acción se puede descubrir la continua coordinación y combinación armónica (EW 1, p. 103).

Así pues, desde sus inicios, el filósofo norteamericano define al hombre como un organismo psicofísico; no obstante, en este primer periodo la unidad del organismo procederá del alma en tanto que elemento trascendente. Esto es, pese a que en esta etapa inicial el cuerpo se presenta como un conjunto de órganos con diferentes capacidades y tendencias, este será el estímulo y el órgano del alma (EW 1, p. 109). El cuerpo es el instrumento orgánico, a través del cual el alma expresa y realiza su propia naturaleza. Por tanto, distingue entre el cuerpo natural, compuesto por los órganos, y el cuerpo experimental, compuesto por cuerpo y alma (EW 1, pp. 112-113).

Esta conexión entre alma y cuerpo también puede encontrarse en el método experimental descrito en su obra Psicología (1886 [1972b]), donde Dewey ya subraya la estructura y rol de los procesos orgánicos como indicadores del modo en que funcionan los procesos psíquicos (P, EW 2, p. 14). De esta manera, aunque en este primer periodo no exista un paralelismo psicofísico, podemos apreciar un concepto funcional de organismo, común a la biología, al idealismo y a la psicología fisiológica, que permite establecer un vínculo conector no sólo entre estas disciplinas, sino también entre las distintas fases de su pensamiento.

\section{De la noción de "organismo" a la de "criatura viva"}

A lo largo del pensamiento deweyano la noción de organismo fue sufriendo transformaciones ante nuevos eventos y situaciones y, pese a que las características básicas se mantuvieron, el filósofo norteamericano fue actualizando su propia noción 
de "organismo" que, finalmente, se transformará en criatura viva en El arte como experiencia (1934 [1989c]). La evolución de esta noción ha sido ampliamente analizada en relación a su proyecto educativo (véanse Thayer, 1968 y Ralston, 2011), mas ha sido descuidada en los estudios dedicados a otras áreas de su pensamiento. En esta sección se plantea una nueva aproximación del término que el autor elabora en la etapa final de su pensamiento, tras conocer a Frederick Matthias Alexander.

Frederick Matthias Alexander (1869-1955) fue un actor australiano que creó una técnica para desarrollar conciencia de nuestros hábitos corporales en nuestro contexto cotidiano cuando empezó a sufrir afonía durante sus actuaciones. El actor se puso frente a un espejo para observar qué es lo que hacía que le pudiera causar dicha afonía y comprobó que había desarrollado un hábito inconsciente. Tras tomar conciencia de estos hábitos, Alexander soluciona su afonía mediante la inhibición; es decir, evitando los hábitos adquiridos recuperó su voz. En este sentido, la clave de su técnica reside en ser plenamente consciente de lo que se está haciendo en ese preciso momento.

La influencia del actor y el creador de la técnica que lleva su nombre ha sido cada vez más reivindicada en la literatura académica (Boydston, 1986; McCormack, 1958; Shusterman, 2008) y el propio Dewey reconoce su valía en su correspondencia y en su obra Experiencia y naturaleza (EN, LW 1, pp. 225; 229). Dewey tuvo su primer encuentro con Alexander en 1916, y poco después él y toda su familia comenzaron a practicar dicha técnica. El influjo de éste es sumamente relevante ya que el actor australiano le proporcionó un mecanismo o técnica desde la cual adquirir conciencia de la unidad cuerpomente. La introducción que el mismo Dewey realiza a la segunda impresión de la obra capital de Alexander, La herencia suprema del hombre, en 1918 pone de relieve la importancia que tuvo en su vida.

En este ensayo Dewey subraya la genialidad de Alexander al mostrar la crisis de la salud física y moral de la sociedad de su tiempo, generada por la escisión entre las funciones psíquicas y físicas (MW 11, p. 350). Según el actor australiano cuando un individuo experimentaba incidentes o episodios problemáticos en su vida el modo habitual para resolverlos era tratarlos desde el aislamiento. Él mismo padeció los problemas de esta crisis cuando sufrió de afonía, ya que los métodos paliativos, en lugar de curar, contribuían a un mayor desajuste en su organismo. Esto se debía a que, cuando los órganos, a través de los cuales se realizan funciones fisiológicas, mentales o sociales, estaban desequilibrados y descoordinados, los 
intentos específicos y limitados para su cura solo ejercían un mayor mecanismo de desorden (MW 11, p. 350).

Por el contrario, el ensayo de Alexander será un libro educativo, no restrictivo, que pretende dar una respuesta que no privilegie una parte del organismo sobre otra. Es decir, la obra propone un método basado en la conciencia corporal, cuya eficacia Dewey no duda en afirmar. En palabras de Dewey:

Él [Alexander] no se detiene en una recomendación moralizadora sobre un tipo de concentración consciente; él posee y ofrece un método definitivo para su realización; e incluso un profano puede testificar, como me alegra hacerlo, de la eficacia de su trabajo en casos concretos (MW 11, p. 351).

En relación a la conciencia corporal hay que aclarar que la importancia concedida a la misma no supone ensalzar el poder de la inteligencia, atribuyéndole un control sobre todas las funciones del organismo. Por el contrario, la técnica corporal consiste en el máximo alargamiento posible de la columna vertebral, al margen de la actividad que estemos realizando. No obstante, hay que aclarar que Alexander nunca fue demasiado claro sobre la técnica por la problemática de presentarla en lenguaje verbal. En su estudio sobre la técnica Alexander, Masiel destaca un triple patrón de acción: dejar el cuello libre; dejar que la cabeza vaya hacia adelante y arriba; y dejar que el torso se alargue y se ensanche (Maisel, 1926, p. 33).

En cualquier caso, lo relevante para estas páginas es que la técnica Alexander consiste en una postura corporal basada en el reconocimiento de nosotros mismos como organismo, asumiendo esa unión cuerpo-mente y reconociendo al cuerpo, en palabras de Dewey, como "la estructura más maravillosa del universo" (MW 11, p. 351).

Siguiendo a Alexander, Dewey critica la tradicional asociación de las formas refinadas del hombre con el cultivo exclusivo de la inteligencia y propone la técnica como método para unir esos dos elementos (cuerpo-mente) que nunca debieron ser separados. Alexander usa los términos "hábito físico" o "hábito corporal" y "hábito mental", para referirse al uso equivocado del aparato sensorio-motor y las ideas fijas de un organismo psicofísico. En su obra muestra cómo estos hábitos se habían convertido en fijos e incontrolables causando una dualidad en el hombre, no sólo a nivel de discusiones teóricas y filosóficas, sino también en la propia conciencia de su cuerpo en la vida cotidiana, generando problemas psicosomáticos (Alexander, 1918, p. 185). 
Por el contrario, el actor mantiene que mente y cuerpo no son entidades separadas, sino funciones continuas que afectan la una a la otra recíprocamente. De hecho dedica el capítulo "Hábitos de pensamiento y del cuerpo" a exponer casos concretos sobre cómo se ha procedido y los problemas derivados del tratamiento surgido por esa escisión entre lo físico y lo psíquico (Alexander, 1918, pp. 73-107). En este sentido, para Dewey el valor de esta propuesta educativa radicará en la reintegración de las funciones que tan desastrosamente se habían dividido, las cuales habían dado primacía a la inteligencia sobre el cuerpo. Así lo indica en la respuesta que da a la reseña de Randolph Bourne acerca de la obra de Alexander, donde dice:

Ciertamente uno de los primeros efectos del conocimiento de los métodos del 'control consciente' es hacernos comprender el carácter superficial y apresurado de los métodos sobre los que confiamos, y la importancia correspondiente de un método fundamental de educación, uno que en el trascurso de la demostración las generaciones integrarán en una coordinación armónica nuestra herencia animal y nuestras capacidades humanas más distintivas (MW 11, p. 355).

El filósofo norteamericano describirá al organismo formado por cuerpo y mente en el periodo final de su vida, y concretamente desde su obra célebre Experiencia y naturaleza. En ella, Dewey propone su naturalismo cultural e introduce la noción de organismo como concepto clave del mismo, describiéndolo como un conjunto que debe ser admitido sin recurrir a ningún tipo de escisión dualista (EN, LW 1, p. 203). Esta unidad psicofísica adquirirá mayor relevancia en el capítulo 7 de esta obra, titulado "Naturaleza, vida y cuerpo-mente", donde introduce su particular noción de "organismo" en contraposición a la tradición filosófica. Dewey realiza una genealogía, comenzando con los griegos y su tratamiento sobre la relación mente, naturaleza y cuerpo.

Según el autor, la dualidad alma-cuerpo que inicia Platón, formulada en base a una concepción de lo supernatural, fue asimilada por el cristianismo, y se convirtió en un problema formalista e irreal con la tradición moderna. Frente a esta tradición, Dewey considera el cuerpo y la mente como estructuras del organismo vivo que se diferencian en cuanto a su función, pero que están en continua interrelación. Cada mente se encuentra en conexión con el cuerpo organizado y cada cuerpo existe en un medio natural con el que sostiene conexiones de adaptación, a través de los procesos organizativos de la mente (EN, LW 1, p. 212). 
De este modo, la mente se despliega teniendo presente el pasado y el futuro, así como las estructuras biológicas del organismo y el propio medio en el que se desarrolla. Es decir, presenta la noción de organismo desde esa continuidad cuerpomente en relación con la naturaleza, describiéndolo como un modo característico de interactuar, el cual no es simultáneo, sino serial, se despliega en el tiempo (EN, LW 1, p. 220). Así, no podemos separar a la criatura viva en cuerpo y mente como tampoco podemos escindir organismo y naturaleza. Dewey propone un modelo de coordinación orgánica total, la psicofísica, que se verá plenamente desarrollada en el artículo publicado en 1928, titulado "Cuerpo y mente" (1989b).

En este ensayo Dewey expone cómo la filosofía, la ciencia y las artes (incluyendo la medicina) en un tiempo pasado estaban unidas, surgiendo las dos primeras a partir de la última (LW 3, p. 25). El filósofo estadounidense recurre a la palabra griega techne, que designaba ciencia y arte, para mostrar esa unidad y considera la escuela de Hipócrates como aquella que supo unir estas disciplinas y consagrarlas. Hipócrates y su escuela tomaron prestado de Heráclito, Empédocles y Pitágoras sus términos e insistieron en la armonía de todos los elementos como condición para mantener y restaurar la salud (LW 3, p. 26). Frente a esta idea de armonía, Dewey destaca los efectos desastrosos de su tiempo, derivados de la división entre mente y cuerpo y apunta la necesidad de restaurar esa unidad como un todo:

\begin{abstract}
Los males que sufrimos en educación, en religión - por ejemplo, el ataque fundamentalista sobre la evolución de los hombres descansa sobre la idea de la separación completa de la mente y el cuerpo- en el materialismo de los negocios y la distancia de los intelectuales de la vida, la separación total de conocimiento y práctica: - todo esto testifica la necesidad de percibir la mente-cuerpo como un todo integral (LW 3, p. 27).
\end{abstract}

El problema de la tradición occidental, a diferencia de otras, dirá Dewey, es que no dispone de una noción para denominar la unidad cuerpo-mente. Por ello, aun cuando se analizaba la relación cuerpo-mente tratando de superar su oposición, los filósofos continuaban manteniendo esa división perpetua. Por el contrario, él considera lo mental y lo corporal como cualidades o funciones de la unidad de acción, subrayando que la separación entre ambas partes tenía sus raíces en la consideración de cuerpo y mente como sustancias separadas (LW 3, p. 28).

Dewey ilustra la imposibilidad de dividirlos en partes aisladas recurriendo al acto de comer. Uno puede comer porque sienta necesidad de comer, porque esté triste o porque esté alegre; comer es, asimismo, un acto social y el temperamento 
emocional de éste hace difícil considerarlo como algo meramente físico. Así, comer pan y beber vino, puede tener implícito actitudes mentales de personas que están asumiendo un aspecto sacramental y espiritual. De este ejemplo se pueden extraer dos consecuencias claras: en primer lugar, que no hay necesidad de establecer líneas que separen unas funciones de otras; $y$, en segundo lugar, que hasta la acción más cotidiana y común de nuestro día a día está cargada de potencial creador, puede ser modificada y dotada de significado por el ser humano.

Por ello, la integración cuerpo-mente en la acción es la demanda más práctica que se le plantea a nuestra civilización. En palabras de Dewey: “[...] la cuestión de la integración mente-cuerpo en la acción es la más práctica de todas las cuestiones que podamos preguntar a nuestra civilización" (LW 3, p. 29). Richard Shusterman se ha hecho eco de esta reivindicación y ha desarrollado una nueva disciplina, a partir del pragmatismo y la filosofía de John Dewey, denominada somaestética, que conjuga teoría y práctica. Shusterman la define como el estudio crítico y meliorativo de la experiencia y el uso del cuerpo; entendido este último como el centro de apreciaciones y creaciones estéticas (Shusterman, 2002, p. 265).

Cuando Dewey introduce el término "criatura viva" en este periodo final, y más concretamente en El arte como experiencia, establece que como organismos vivos, formados por la unidad cuerpo-mente, estamos conformados por nuestras continuas interacciones con nuestro medio y con las personas de nuestro alrededor. El hombre no es un ser aislado, sino una criatura viva conformada por esa unidad cuerpo-mente en continuo cambio.

Dewey instaura en su última etapa una nueva propuesta ontológica que pretende superar los dualismos heredados. Lo que se va a reivindicar, por tanto, no es la unidad del ser humano, sino esa idea de interrelación y cambio en un contexto determinado. Las criaturas vivas, por tanto, no son individuos aislados, divisibles y analizables, sino que están en un continuo construirse, a través de esas modificaciones que va sufriendo en su interacción con el medio, en ese proceso de búsqueda de su propia armonía. Por ello, la noción de "naturaleza" y nuestra inagotable relación con la misma tendrán un papel de vital importancia en su proyecto filosófico. Las criaturas vivas no pueden olvidar las condiciones naturales desde las que se constituyen y desarrollan, pero también se modifican. Por ello, la noción de "organismo" de Dewey hay que entenderla desde la continuidad con la noción de "naturaleza", como se expone en la siguiente sección. 


\section{La criatura viva en continua construcción}

Dewey va a proponer una nueva ontología caracterizada por la continuidad entre criatura y medio en la inmediatez de las situaciones, rechazando las posiciones realistas e idealistas. Estas teorías intelectualistas, según el filósofo, reducían todo a un modo de conocimiento que no era fiel a la realidad, e introducían una serie de dualismos y distinciones que habían llevado a la filosofía y a la psicología a las más desastrosas consecuencias. En cambio, el filósofo estadounidense adopta una metafísica emergentista que, como ha destacado Carlos Mougán, posibilitará la continuidad entre naturaleza y experiencia (Mougán, 2000, p. 150).

Dewey rechaza el realismo metafísico y desarrolla una ontología que pone el acento en las situaciones, en esos eventos en los que la experiencia emerge en un continuo fluir. Por ello la noción de criatura viva hay que entenderla desde este principio de continuidad en la que no hay una distinción entre el hombre y la naturaleza, sino que ambos están en continua interrelación. Ahora bien, ¿qué entendemos por el principio de continuidad?

El principio de continuidad es una idea presente en toda la obra de Dewey y puede rastrearse en pragmatistas previos como Charles S. Peirce, quien la define y la sitúa como la "clave maestra de la filosofía". Siguiendo la terminología griega, Peirce la denomino "synechismo" y la sitúa define como uno de los principios fundamentales de su filosofía. En palabras del filósofo:

\footnotetext{
Durante dos siglos hemos añadido -ista e-ismo a las palabras para señalar las doctrinas que exaltan la importancia de aquellos elementos que la palabra raíz significa. Así, materialismo es la doctrina de que la materia lo es todo, idealismo la doctrina de que las ideas lo son todo, dualismo la filosofía que separa todo en dos. De alguna manera, propongo que sinejismo significa la tendencia a considerar todo como un continuo (Peirce, 2001).
}

Por su parte Dewey, a lo largo de sus reflexiones sobre educación, naturaleza, investigación, metodología. Considérese su obra Lógica. Teoría de la investigación (1939 [1989d]) donde dice: "El crecimiento y el desarrollo de cualquier organismo vivo desde la semilla hasta la madurez ilustra el significado de continuidad" [L, LW 12, pp. 12:30; L, p. 39]; así como Democracia y educación (1916 [1983b]) donde expone: "El proceso educativo es un proceso continuo de crecimiento, que tiene como su objetivo en cada etapa una capacidad adicional de crecimiento" 
(DE, MW 9, p. 59; De, p. 56). Sin embargo, nunca ofreció una definición clara o específica del mismo.

En un sentido amplio, podemos definir el principio de continuidad como ese proceso de crecimiento que emerge en la situación, el cual implica una teoría creativa de la temporalidad humana. En palabras de Dewey:

La realidad es el proceso de crecimiento en sí mismo; la infancia y la madurez son fases de un continuo, en el que solo porque es una historia, lo posterior no puede existir hasta que exista lo anterior ('materialismo mecanicista' en germen); y en el que el último hace uso del resultado registrado y acumulado del anterior -0 , más estrictamente, es su utilización ('teleología espiritualista' en germen) (EN, LW 1, p. 210).

En su estudio sobre la noción de "continuidad" deweyana, Thayer ha proporcionado algunas características como unificación, crecimiento, progreso, integración, todo, en oposición a la discontinuidad que implicaría ruptura, pausas, interrupciones, dualismos o fragmentación (Thayer, 1968, p. 174). En relación con el término de criatura viva del que se ocupan estas páginas, este principio de continuidad habrá que comprenderlo desde la idea de crecimiento de la vida, como algo que nunca se acaba.

El proceso de vida está caracterizado por actividades que, aun teniendo mayor o menor éxito, depende de esa incesante interacción con el medio; en el que la criatura busca mantener el equilibrio, la armonía. Por ello, pese a que en esa interacción se pueden producir rupturas, la criatura viva tiene la necesidad de restablecer ese equilibrio (L, LW 12, p. 34; L, p. 41); y Dewey no atribuye esta característica sólo al ser humano, sino también al resto de criaturas vivas (L, LW 12, p. 33; L, p. 41). No obstante, el filósofo aclarará que se requiere un mayor esfuerzo para restaurar el equilibrio cuanto más elevado sea el organismo. En este sentido, el hombre está realizándose a sí mismo continuamente y ese hacerse es un arte. En otras palabras, Dewey pone el énfasis no tanto en la noción de criatura viva como sustancia, sino como proceso en continuo cambio, criatura troquelada por la interacción con su medio.

Las cualidades que caracterizan el principio de continuidad deweyano reivindican la dimensión creativa del ser humano y propone una ontología de los eventos que está en continua construcción. Por ello, Dewey no desarrolla una teoría de la verdad con mayúsculas o asume la existencia de un orden preestablecido y 
fijo, sino que se ocupa de las acciones humanas que tratan de alcanzar un modo armónico de vida. Se trata, como ha reivindicado Lewis E. Hahn, de una filosofía contextualista (Hahn, 1998, p. 37), una filosofía del cambio, según la cual los hechos no son algo pasado o finalizado, sino algo dinámico, presencias vivas que permiten el desarrollo de un importante modo de hacer nuestro mundo (Hahn, 1998, p. 74).

Ahora bien, esto no implica que el naturalismo de Dewey, como propone George Santayana, reduzca la naturaleza a un punto de vista particular (Santayana, 1989, p. 373). El filósofo de ascendencia española, el cual se auto-denomina a sí mismo filósofo naturalista, acusa a Dewey de elaborar un "naturalismo a medias" y de ignorar e incluso idealizar una naturaleza, que no es propiamente humana, reduciéndola a mero antropomorfismo. Sin embargo, como ha puesto de relieve Larry Hickman, en esa relación hombre-medio que se da a través de la experiencia, la criatura viva es un elemento más que construye y se construye en dicha interacción (Hickman, 2007, p. 133). En otras palabras, no se minusvalora o restringe la naturaleza a la criatura viva, sino que se pone el acento en la interdependencia de ambas partes y el campo de infinitas relaciones que esta genera.

\section{Conclusión}

A modo de conclusión, me gustaría apuntar la importancia de la noción de criatura viva que el filósofo estadounidense propone. Dewey introduce este término dentro del proyecto ontológico que conforma su propuesta naturalista. El término "criatura viva" lo caracteriza desde la emergencia de la experiencia; en ese proceso de continua interacción entre el hombre y el medio. En este sentido, el filósofo no elaborará una teoría de la verdad, ni sumirá la existencia de un orden preestablecido y fijo, sino que se ocupará de esa continua interrelación por las que se van desplegando momentos de equilibrio y armonía.

En otras palabras, en el naturalismo de Dewey la relación con el mundo no está caracterizada por ser una lucha; lo externo al sujeto no se plantea en oposición a él, como aquello que molesta o debe ser objeto de dominio o conocimiento, sino como un ámbito de infinitas posibilidades en el que el hombre puede llegar a desarrollar sus más amplias potencialidades. Pese a que en estas páginas sólo se ha atendido a la dimensión ontológica, será desde este marco desde el que Dewey propondrá su propuesta naturalista, caracterizada por el tratamiento de esos dos componentes: el metodológico y el ontológico. 


\section{Referencias}

Alexander, F. M. (1918). Man's Supreme Inheritance. New York: E. P. Dutton and Co.

Alexander, Th. M. (2013). The Human Eros. Eco-ontology and the Aesthetics of Existence. New York: Fordham University Press.

Boydston, J. A. (1986). John Dewey and Alexander Technique. Recuperado de http://www. alexandercenter.com/jd/deweyalexanderboydston.html

Dewey, J. (1972a). Soul and Body. En J. A. Boydston (Ed.), The Early Works of John Dewey: 1882-1896 (vol. 1, pp. 93-115). Carbondale: Southern Illinois University Press.

Dewey, J. (1972b). Psychology. En J. A. Boydston (Ed.), The Early Works of John Dewey: 1882-1896 (vol. 2). Carbondale: Southern Illinois University Press.

Dewey, J. (1983a). The Influence of Darwin on Philosophy. En J. A. Boydston (Ed.), The Middle Works of John Dewey: 1899-1924 (vol. 4, pp. 3-14). Carbondale: Southern Illinois University Press. (2010). La influencia del darwinismo en la filosofía (A. Faerna, Trad.). En A. Faerna (Ed.), La miseria de la espistemología. Ensayos de pragmatismo (pp. 49-60). Madrid: Biblioteca Nueva.

Dewey, J. (1983b). Democracy and Education. En J. A. Boydston (Ed.), The Middle Works of John Dewey: 1899-1924 (vol. 9). Carbondale: Southern Illinois University Press. (1995) Democracia y educación (L. Luzuriaga, Trad.). Madrid: Morata.

Dewey, J. (1989a). Experience and Nature. En J. A. Boydston (Ed.), The Later Works of John Dewey: 1925-1953 (vol. 1). Carbondale: Southern Illinois University Press.

Dewey, J. (1989b). Body and Mind. En J. A. Boydston (Ed.), The Later Works of John Dewey: 1925-1953 (vol. 3, pp. 25-40). Carbondale: Southern Illinois University Press.

Dewey, J. (1989c). Art as Experience. En J. A. Boydston (Ed.), The Later Works of John Dewey: 1925-1953 (vol. 10). Carbondale: Southern Illinois University Press. (2008) El arte como experiencia (J. Claramonte Arrufat, Trad.). Barcelona: Paidós.

Dewey, J. (1989d). Logic. The Theory of Inquiry. En J. A. Boydston (Ed.), The Later Works of John Dewey: 1925-1953 (vol. 14). Carbondale: Southern Illinois University Press. (1950) Lógica: teoría de la investigación (E. Imaz, Trad.). México: Fondo de Cultura Económico.

Haack, S. (1993). Evidence and Inquiry: Towards Reconstruction in Epistemology. Oxford y Cambridge: Blackwell Publishing.

Hahn, L. E. (1998). Enhancing Cultural Interflow Between East and West: Collected Essays in Comparative Philosophy and Culture. Anhui: Thome H. Fang Institute.

Hahn, S. S. (2007). Contradictions in Motion. Hegel's Organic Concept of Life and Value. New York: Cornell University Press.

Hall, G. S. (1912). Founders of Modern Psychology. New York: D. Appleton and Company. Hegel, G. W. F. (1997). Enciclopedia de las ciencias filosóficas (R. Valls Plana, Trad.). Barcelona: Alianza Editorial. 
Hegel, G. W. F. (1966). Fenomenología del espíritu (W. Roces, Trad.). México: Fondo de Cultura Económica.

Hickman, L. (2007). Pragmatism as Postmodernism: Lessons from John Dewey. New York: Fordham University Press.

Huxley, T. H. (1866). Lessons in Elementary Physiology. London: Macmillan and Co.

Maisel, E. (1995). La técnica Alexander. Barcelona: Paidós.

McCormack, D. (1958). Frederick Matthias Alexander and John Dewey. A Neglected Influence (Tesis doctoral). University of Toronto, California. https://www.alexandertechnique.com/ articles/dewey/alexanderdewey.pdf

Mougán Rivero, J. C. (2000). Acción y racionalidad. Actualidad de la obra de John Dewey. Cádiz: Universidad de Cádiz.

Papineau, D. (2015). Naturalism. En Stanford Encyclopedia of Philosophy. doi: http://plato. stanford.edu/entries/naturalism/.

Peirce, Ch. S. (2001). La inmortalidad a la luz del sinejismo (M. Revuelta, Trad.). http://www. unav.es/gep/ImmortalityInLightSynechism.html.

Ralston, S. J. (2011). A more Practical Pedagogical Idea: Searching for a Criterion of Deweyan Growth. Educational Theory, 61(3), 351-364.

Rorty, R. (1982). Consequences of Pragmatism. Hassocks: Harvester Press.

Thayer, H. S. (1968). Meaning and Action: a Critical History of Pragmatism. Indianapolis: Bobbs-Merrill.

Santayana, G. (1989). Dewey's Naturalistic Metaphysic. En J. A. Boydston (Ed.), The Later Works of John Dewey: 1925-1953 (vol. 3, pp. 673-688). Carbondale: Southern Illinois University Press.

Shusterman, R. (2002). Pragmatist Aesthetics: Living Beauty, Rethinking Art. Oxford and Cambridge, Mass.: Blackwell.

Shusterman, R. (2008). Body Consciousness: A Philosophy of Mindfulness. Cambridge: Cambridge University Press.

Wundt, W. (1910). Principles of Physiological Psychology. New York: Macmillan Co. 